\title{
HUBUNGAN LAMA KERJA DAN KEBISINGAN DENGAN STRES KERJA PADA PEKERJA UNIT PRODUKSI PAVING BLOCK DI UD. RIZKI ASSILA ULFA LUBUK PAKAM KABUPATEN DELI SERDANG
}

\section{Anggi Isnani Parinduri,Luci Riani Br Ginting, Irmayani, Risa Elvira Prabaja}

\author{
Program Studi Kesehatan Masyarakat Fakultas Kesehatan Masyarakat \\ Institut Kesehatan Medistra Lubuk Pakam \\ Jl. Sudirman No.38 Lubuk Pakam Kec.Lubuk Pakam Kab. Deli Serdang, \\ Sumatera Utara \\ Email: anggisnani@gmail.com
}

\section{DOI : https://doi.org/10.35451/jkg.v3i1.518}

\begin{abstract}
In line with current industrial growth which requires labor as the dominant element that manages raw materials, machinery, equipment and other processes in the workplace. Each workplace contains a variety of potential hazards that can affect the health of the workforce or can cause occupational diseases that are work stress. The purpose of this study is to describe the relationship between work duration and noise and work stress in paving block production unit workers at UD. Rizki Assila Ulfa Lubuk Pakam Deli Serdang Regency 2020. This research uses analytical descriptive method using cross sectional design. The population in this study were 30 paving block production unit workers with the sampling technique using Total Sampling. Data analysis was performed univariately and bivariately using the Chi-Square statistical test with $a=0.05$. The results of the analysis show that there is a relationship between work duration and noise with work stress on paving block production unit workers at UD. Rizki Assila Ulfa Lubuk Pakam Deli Serdang Regency in 2020, namely the length of work $p$ value (0.005) <a (0.05), and noise $p$ value $(0.031)<a(0.05)$. Based on the results of research it is recommended to workers that workers condemn personal protection by using Personal Protective
\end{abstract}


Equipment (PPE) such as ear plugs that can protect the ears from noise caused by machines, so as to reduce exposure to noise that can interfere with health.

\section{Keywords: work duration, noise, work stress}

\section{PENDAhUluAN}

Pertumbuhan industri sekarang ini

memerlukan tenaga kerja sebagai unsu $r$ dominan yang mengelola bahan baku, mesin, peralatan dan proses lainnya ditempat kerja, yang bertujuan untuk menghasilkan suatu produk yang bermanfaat bagi masyarakat (Budiono, 2013). Faktor fisik yang terdapat di lingkungan kerja adalah kebisingan, merupakan suara atau bunyi yang tidak dikehendaki dan dapat menyebabkan gangguan bagi pekerja jika terpapar terus-menerus (Suma'mur, 2014). Nilai maksimum yang dapat diterima oleh pekerja dari kebisingan berdasarkan Permenaker Nomor 5 Tahun 2018 untuk waktu pemaparan 8 jam kerja adalah $85 \mathrm{~dB}$, jika tingkat kebisingan semakin tinggi maka waktu pemaparan juga semakin berkurang. Salah satu faktor yang dapat menyebabkan gangguan kesehatan adalah jika lingkungan kerja terdapat kebisingan yang melebihi ambang batas. Selain dapat menimbulkan gangguan kesehatan seperti tuli sementara dan tuli permanen, kebisingan dapat menyebabkan gangguan psikologis seperti rasa tidak nyaman, konsentrasi berkurang dan emosi. Apabila pekerja melakukan pekerjaannya dengan kondisi yang tidak nyaman maka dapat menimbulkan stres kerja. Intensitas kebisingan membuat penurunan performa dalam melakukan pekerjaan, stres akibat kerja oleh karena pemaparan bising yang terus-menerus dapat menyebabkan terjadinya kelelahan, kegelisahan, depresi, emosi tidak stabil dan kegelisahan serta dapat menyebabkan gangguan tidur. Masalah stres telah merugikan organisasi 300 miliar dari segi pergantian biaya perawat, kompensasi para pekerja, absensi, dan tingkat keluar masuk tenaga kerja. Biaya perawatan untuk kesehatan hampir $50 \%$ lebih besar untuk para pekerja yang mengalami stres tinggi dalam pekerjaan mereka. Berdasarkan data departemen dalam negeri diperkirakan bahwa sekitar $40 \%$ dari keluar masuknya tenaga kerja disebabkan oleh masalah stres, yang didasari oleh kenyataan bahwa 60-90\% kunjungan kedokteran dengan masalahmasalah yang berkaitan dengan stres (Losyk, 2005). Berdasarkan hasil studi pendahuluan yang telah dilakukan di area produksi Paving Block, Bodem, Kasteen ini memiliki 30 pekerja, dalam proses pengolahannya, pabrik menggunakan mesin-mesin dengan intensitas kebisingan yang cukup tinggi serta jam kerja yang hanya 1 shift 
dimana pekerja harus melakukan pekerjaannya lebih dari 8 jam setiap harinya yang dapat mengakibatkan stres kerja. Pabrik tersebut memiliki tingkat kebisingan yang cukup tinggi, pada mesin press paving block tingkat kebisingan sebesar 94,5 dB dan tingkat kebisingan terendah terdapat di bagian pengaduk semen dengan tingkat kebisingan sebesar 84,1 dB. Adapun tujuan dari penelitian ini adalah untuk mengetahui hubungan lama kerja dan kebisingan dengan stres kerja pada pekerja unit produksi paving block di UD. Rizki Assila Ulfa Lubuk Pakam Kabupaten Deli Serdang.

\section{METODE PENELITIAN}

Jenis penelitian yang digunakan pada penelitian ini yaitu penelitian kuantitatif dengan pendekatan survey analitik, menggunakan desain penelitian yaitu cross sectional yang bertujuan untuk menjelaskan hubungan lama kerja

dan kebisingan dengan stres kerja pada pekerja unit produksi paving bloc k di UD. Rizki Assila Ulfa Lubuk Pakam Kabupaten Deli Serdang yang diukur dan dikumpulkan pada waktu yang bersamaan dan dilakukan pada situasi saat yang sama (Sugiyono, 2010). Populasi dalam penelitian ini adalah seluruh pekerja unit produksi Paving Block di UD. Rizki Assila Ulfa Lubuk Pakam Kabupaten Deli Serdang yang berjumlah 30 orang. Pengambilan sampel dengan menggunakan tekhnik
Total sampling yaitu seluruh populasi dijadikan sampel. Pengumpulan data dengan menggunakan data primer dan data sekunder. Wawancara kepada responden dengan berpedoman pada kuesioner yang telah dipersiapkan merupakan teknik yang digunakan dalam mengumpulkan data primer. Sedangkan data sekunder diperoleh dari UD. Rizki Assila Ulfa Lubuk Pakam. Setelah data terkumpul, kemudian diolah dengan menggunakan uji chi square dengan tingkat kepercayaan 95\% (alpha $=5 \%)$. Dasar pengambilan keputusan dengan ketentuan jika nilai $p$ < a maka Ho ditolak yang dapat disimpulkan bahwa terdapat hubungan antara variabel independen dengan dependen. Variabel penelitian terdiri dari variabel independen yaitu lama kerja dan kebisingan. Variabel dependen adalah stres kerja.

\section{HASIL}

Usaha Dagang Rizki Assila Ulfa berdiri pada tahun 2010 yang awal pembuatan nya dimulai dari pembuatan Paving Block, Bodem dan Kasteen dimana seharinya pembuatan Paving Block memproduksi $\leq 26.000$ dengan menggunakan mesin press. Jumlah pekerja sebanyak 30 orang. Usaha Dagang Rizki Assila Ulfa berada di Desa Sidourip yang merupakan satu desa dari 11 Desa di Kecamatan Beringin, Kabupaten Deli Serdang Provinsi Sumatera Utara. Berbatasan langsung dengan Bandara Internasional 
Kualanamu di bagian timur, Desa Araskabu di bagian barat, Desa Pasar V Kebun Kelapa di bagian selatan dan Kecamatan Pantai Labu di bagian utara. Tabel 1. Distribusi Karakteristik Pekerja Unit Produksi

\begin{tabular}{|c|c|c|}
\hline $\begin{array}{c}\text { Karakteristik } \\
\text { Pekerja }\end{array}$ & $\mathbf{f}$ & $\%$ \\
\hline \multicolumn{3}{|l|}{ Umur } \\
\hline$<24$ tahun & 1 & 33,3 \\
\hline 25-25 tahun & 5 & 16,7 \\
\hline$>36$ tahun & 24 & 80,0 \\
\hline \multicolumn{3}{|l|}{ Jenis Kelamin } \\
\hline Laki-laki & 24 & 80,0 \\
\hline Perempuan & 6 & 20,0 \\
\hline \multicolumn{3}{|l|}{ Pendidikan Terakhir } \\
\hline SD & 10 & 33,3 \\
\hline SMP & 14 & 46,7 \\
\hline SMA & 6 & 20,0 \\
\hline \multicolumn{3}{|l|}{ Masa Kerja } \\
\hline$\leq 6$ tahun & 23 & 76,7 \\
\hline$>6$ tahun & 7 & 23,3 \\
\hline Total & 30 & 100,0 \\
\hline
\end{tabular}

Tabel 1 menunjukkan bahwa dari 30 orang pekerja di unit produksi paving block, mayoritas responden berumur > 36 tahun sebanyak 24 orang ( $80 \%)$, jenis kelamin laki-laki sebanyak 24 orang $(80 \%)$, pendidikan terakhir SMP sebanyak 14 orang $(46,7 \%)$, dan masa kerja $\leq 6$ tahun sebanyak 23 orang $(76,6 \%)$.

Tabel 2. Distribusi Responden Berdasarkan Lama Kerja

\begin{tabular}{ccc}
\hline Lama Kerja & $\mathbf{f}$ & $\%$ \\
\hline$\leq 8$ jam & 6 & 20,0 \\
$>8$ jam & 24 & 80,0
\end{tabular}

\begin{tabular}{lll}
\hline Total & 30 & 100,0 \\
\hline
\end{tabular}

Tabel 2 menunjukkan bahwa sebagian besar responden mempunyai lama kerja $>8$ jam per hari yaitu sebanyak 24 orang (80\%).

Tabel 3. Distribusi Responden Berdasarkan Kebisingan

\begin{tabular}{ccc}
\hline Kebisingan & $\mathbf{f}$ & $\mathbf{\%}$ \\
\hline$\leq 85 \mathrm{~dB}$ & 15 & 50,0 \\
$>85 \mathrm{~dB}$ & 15 & 50,0 \\
\hline Total & $\mathbf{3 0}$ & $\mathbf{1 0 0 , 0}$ \\
\hline
\end{tabular}

Berdasarkan Tabel 3 dapat diketahui bahwa pekerja yang berada di lingkungan kebisingan dengan tingkat kebisingan $\leq 85 \mathrm{~dB}$ sebanyak 15 orang (50\%) dan pekerja yang berada di lingkungan dengan tingkat kebisingan > $85 \mathrm{~dB}$ sebanyak 15 orang (50\%).

Tabel 4. Distribusi Responden Berdasarkan Stres Kerja

\begin{tabular}{ccc}
\hline Stres Kerja & $\mathbf{f}$ & $\mathbf{\%}$ \\
\hline Sedang & 23 & 76,7 \\
Berat & 7 & 23,3 \\
\hline Total & $\mathbf{3 0}$ & $\mathbf{1 0 0 , 0}$ \\
\hline
\end{tabular}

Berdasarkan Tabel 4 dapat diketahui bahwa mayoritas pekerja yang mengalami stres sedang sebanyak 23 orang $(76,7 \%)$.

Tabel 5. Hubungan Lama Kerja dan Kebisingan dengan Stres Kerja

\begin{tabular}{lll}
\hline Variabel & Stres Kerja & palue \\
\hline
\end{tabular}




\begin{tabular}{|c|c|c|c|c|c|}
\hline & \multicolumn{2}{|c|}{ Sedang } & \multicolumn{2}{|c|}{ Berat } & \\
\hline & $\mathbf{n}$ & $\%$ & $\mathbf{n}$ & $\%$ & \\
\hline \multicolumn{6}{|c|}{ Lama Kerja } \\
\hline$\leq 8$ jam & 2 & 6,7 & 4 & 13,3 & 0,005 \\
\hline$>8$ jam & 21 & 70,0 & 3 & 10,0 & \\
\hline \multicolumn{6}{|l|}{ Kebisingan } \\
\hline$\leq 85 \mathrm{~dB}$ & 14 & 46,7 & 1 & 3,3 & 0,031 \\
\hline$>85 \mathrm{~dB}$ & 9 & 30,0 & 6 & 20,0 & \\
\hline
\end{tabular}

Tabel 5 menunjukan bahwa dari 6 pekerja yang memiliki lama kerja $\leq 8$ jam/hari terdapat 2 pekerja $(6,7 \%)$ yang mengalami stres sedang, dan 4 pekerja $(13,3 \%)$ yang mengalami stres berat. Dari 24 pekerja yang memiliki lama kerja $>8$ jam/hari sebanyak 21 pekerja $(70,0 \%)$ yang mengalami stres sedang, dan 3 pekerja $(10,0 \%)$ yang mengalami stres berat.

Tabel 5 menjelaskan bahwa berdasarkan hasil analisis antara lama kerja dengan stres kerja diperoleh nilai p. $=0,005<a=0,05$ yang artinya terdapat hubungan yang signifikan antara lama kerja dengan stres kerja, dan hasil analisis antara kebisingan dengan stres kerja diperoleh nilai $\mathrm{p}=$ $0,031<a=0,05$ yang artinya terdapat hubungan yang signifikan antara kebisingan dengan stres kerja.

\section{PEMBAHASAN}

Berdasarkan hasil yang didapatkan menunjukkan bahwa dari 30 responden, terdapat 6 pekerja (20\%) yang memiliki lama kerja $\leq 8$ jam per hari dan 24 orang (80\%) memiliki lama kerja $>8$ jam hari (Tabel 2).

Menurut John Ridley (2016) lamanya seseorang bekerja dengan bai k dalam sehari pada umumnya 6-8 jam. Sisanya dipergunakan untuk kehidupan dalam keluarga dan masyarakat, istirahat, tidur, dan lain-lain. Menurut Suma'mur (2014) dalam seminggu seseorang biasanya dapat bekerja dengan baik selama 40-50 jam. Lebih dari itu, kemungkinan besar untuk timbulnya hal yang negatif bagi tenaga kerja yang bersangkutan dan pekerjaannya itu sendiri. Semakin panjang waktu kerja dalam seminggu, semakin besar kecenderungan terjadinya hal yang tidak diinginkan. Berdasarkan asumsi penelitian memperpanjang waktu kerja lebih dari kemampuan lama kerja biasanya tidak disertai dengan efisiensi, efektivitas dan produktivitas kerja yang optimal dan bahkan biasanya terlihat penurunan di kualitas dan hasil kerja serta bekerja dengan waktu yang berkepanjangan dapat timbul kecenderungan untuk terjadinya kelelahan kerja, gangguan kesehatan, penyakit akibat kerja dan kecelakaan serta ketidakpuasan dalam bekerja.

Berdasarkan hasil pengukuran yang diperoleh dari 2 titik pengukuran dan diperoleh hasil pengukuran 1 titik dibawah NAB dan 1 titik diatas NAB. Menurut Permenaker Nomor 5 tahun 2018 mengenai Keselamatan dan Kesehatan Kerja Lingkungan Kerja bahwa faktor bahaya (kebisingan) yang dapat diterima tenaga kerja dalam 
pekerjaan sehari-hari tidak lebih dari 8 jam dalam satu hari atau 40 jam dalam seminggu. Berdasarkan asumsi peneliti jika nilai kebisingan yang telah melebihi 85 dB maka sebaiknya dibuat sistem rotasi kerja sehingga tidak mengganggu jalannya proses produksi karena kebisingan di bagian unit produksi paving block yang melebihi nilai ambang batas. Kebisingan yang bersumber dari mesin produksi dapat dikendalikan dengan beberapa cara, seperti perawatan pada mesin dengan mengganti komponen mesin

yang sudah

tua, aus atau mengeras dan melakukan pelumasan pada bagian-bagian mesin yang bergesekan, termasuk penggunaan

pelumas pada proses machining (bubut dan sejenisnya), pengencangan bagianbagian mesin yang mulai longgar, terutama bagian yang dihubungkan dengan sambungan baut (Tambunan, 2005). Selain itu, kebisingan dapat dikendalikan dengan menggunakan alat pelindung telinga jenis sumbat telinga atau ear plug pada pekerja. Alat pelindung telinga tersebut dapat mengurangi intensitas kebisingan sekitar 25-30 dB (Budiono, 2013).

Berdasarkan hasil yang didapat peneliti menunjukkan bahwa dari 30 responden, yang mengalami stres sedang sebanyak 23 orang $(76,7 \%)$ dan pekerja yang mengalami stres berat sebanyak 7 orang (23,3\%). Menurut
Handoko (2016), stres adalah suatu kondisi yang mempengaruhi keadaan fisik atau psikis seseorang karena adanya tekanan dari dalam ataupun luar diri seseorang yang dapat mengganggu

pelaksanaan kerja mereka. Stres yang terlalu besar dapat mengancam kemampuan seseorang untuk menghadapi lingkungan. Stres kerja merupakan perasaan yang menekan atau merasa tertekan yang dialami pekerja dalam menghadapi suatu pekerjaan di tempat kerja. Selain itu, stres juga dapat menjadi bagian dari masalah di luar lingkungan pekerjaan, sehingga masalah di belakang layar dalam keluarga atau lingkungan sosial dapat bermanifes sebagai gejala stres

di tempat kerja dan membuat pengungkapan gejala stres ini menjadi lebih menyulitkan.

\section{KESIMPULAN}

Kesimpulan pada penelitian ini yaitu:

a. Pekerja paving block yang mengalami stres sedang sebanyak 23 orang $(76,7 \%)$.

b. Lama Kerja pada pekerja paving block mayoritas > 8 jam dan terdapat 1 titik kebisingan yang melebihi NAB yaitu sebesar 94,5 dB.

c. Hasil uji chi-square menunjukkan adanya hubungan yang bermakna antara lama kerja dengan stres kerja dengan nilai $p$ sebesar 0,005 
$(p<0,05)$ dan terdapat hubungan yang bermakna antara kebisingan dengan stres kerja dengan nilai $p$ sebesar $0,031(p<0,05)$.

\section{DAFTAR PUSTAKA}

A.M. Sugeng Budiono. (2013). Bunga Rampai Hiperkes \& KK Edisi Kedua (revisi). Semarang: Badan Penerbit Universitas Diponegoro Handoko, T Hani. (2016). Manajemen Personalia dan Sumber Daya Manusia. Yogyakarta: BPFE

John Ridley, dkk. (2008). Kesehatan dan Keselamatan Kerja. Jakarta: Erlangga

Losyk, B. (2005). Kendalikan Stres Anda. Jakarta : Gramedia Pustaka Utama

NIOSH. (2014). Observation-Based Posture Assessment: Review of Current Practice and Recommendations for Improvement, National Institute for Occupational Safety and Health, Cincinnati

Peraturan Menteri Ketenagakerjaan Republik Indonesia Nomor 5 Tahun (2018) Tentang Keselamatan dan Kesehatan Kerja Lingkungan Kerja: Nilai Ambang Batas Faktor Kimia

Sugiyono. (2010). Metode Penelitian

Pendidikan (Pendekatan

Kuantitatif dan Kualitatif).
Suma'mur. (2014). Higiene Perusahaan dan Kesehatan Kerja (Hiperkes). Edisi Kedua. Cetakan Pertama. Jakarta: Sagung Seto

Tambunan, Sihar Tigor Benjamin. (2005). Kebisingan di Tempat Kerja (Occupational Noise). Yogyakarta: Andi Offsset

Tarwaka, dkk. (2004). Ergonomi Untuk Kesehatan Kerja dan Produktivitas. Surakarta: UNIBA Pers 